\title{
Low-cost drifting buoys for surface water observations in wetlands
}

\author{
Marco Julio Ulloa ${ }^{1}$ (1) - Manuel Antonio Arenas-Méndez ${ }^{2}$
}

(c) Springer Nature Switzerland AG 2019

\begin{abstract}
Low-cost technologies are needed in developing and least-developed countries to improve monitoring capabilities to determine the dispersion characteristics of inland and coastal waters. Thus, the objective of the paper is to describe the design and construction of a low-cost saucer-shaped drifter, including its internal electronics, remote-control unit, and software. The system can operate over short timescales and distances and is thus suitable for estimating dispersion coefficients and differential kinematic properties of the fluid. The drifter was constructed primarily from readily available plastic products. The main electronic components were a global positioning receiver, microcontroller, lithium-polymer battery, wireless communication module, and activation and battery status indicators. The electronic design simplifies operation because the stored positions can be transferred to a computer via a mini-universal serial bus port without having to open the buoy. In addition, communication between the control unit and saucer-shaped drifter and its memory enhances its operational capability in the field. Water tightness tests were successful, and the operation of electronics was tested at a wetland known as Estero Topila, México, to infer dispersion characteristics using a trio of drifters. Agreement with the Richardson's 4/3 power law provides reliability of the electronics system performance and measured data.
\end{abstract}

Keywords Drifting buoys · Relative dispersion $\cdot$ Small-scale turbulence $\cdot$ Coastal wetlands $\cdot$ Inland lagoons

\section{Mathematics Subject Classification 76F25}

JEL Classification Q53·Q55

\section{Introduction}

The advection of a parcel of fluid can undergo extensive rotation and deformation simultaneously. Vorticity is a measure of the rigid body rotation of a particle of fluid, and deformation is always accompanied by changes in the separation of particles. Wetlands are an interface between aquatic and terrestrial environments [1]. Freshwater wetland ecosystems are away from the complication of oceanic motions [2], thereby representing ideal environments for the study of the dominant mechanism (rotation versus background deformation) in the horizontal dispersion of a fluid parcel, an important subject in the study of eddying motion of turbulent flows [3-5]. Lagrangian drifting buoys or drifters are water motion tracers commonly used for quantitative measurements of the spatial structure of the current field, dispersion coefficients, and the differential kinematic properties of the fluid [4-9]. The drifters must record their positions autonomously to avoid perturbations to the flow. Saucer-shaped drifting buoys, in particular, were first used to track oil spills from several hours to a few days [10-12]. It is noteworthy that these drifting buoys were specifically designed to emulate the motion of a surface oil slick, a design that was adjusted over years until they tracked oil spill [11, 12]. In general, pollutants move at their own rates, and thereby, drifters should not be used to

$\triangle$ Marco Julio Ulloa, sidescansonar2003@yahoo.com.mx $\left.\right|^{1}$ Instituto Politécnico Nacional, Centro de Investigación en Ciencia Aplicada y Tecnología Avanzada, Unidad Altamira, Km 14.5 Carretera Tampico-Puerto Industrial de Altamira, 89600 Altamira, Tamaulipas, México. ${ }^{2}$ Instituto Tecnológico Superior de Pánuco, Prolongación Avenida Artículo Tercero s/n, 93998 Pánuco, Veracruz, México.

SN Applied Sciences (2019) 1:430 | https://doi.org/10.1007/s42452-019-0444-1 
follow contaminants if each buoy has not been calibrated and the design adjusted to the intended contaminant is being monitored. Saucer-shaped drifting buoys consist of two identical domes with a vertical stabilizing ring extending around the center of the buoy. Power supply and electronics are all inside the domes. The location of buoys has been obtained using the global positioning system (GPS) and telemetry.

The access of technological advances with respect to training and financing is difficult in developing and leastdeveloped countries. There is a need for these counties in building up their own capabilities to reduce costs. Clearly, inexpensive, user-friendly, autonomous drifters suitable for estuarine waters and relatively small-scale aquatic bodies are needed to estimate dispersion coefficients, Lagrangian integral timescales, and water velocity. In particular, we need designs capable of following flows through the narrow channels that connect rivers with freshwater lagoons. By floating freely as neutrally buoyant particles (passive tracers), drifters should also be able to cross areas covered by submerged and emergent macrophyte habitats forming islets and intricate networks of channels with minimal entrapments. Furthermore, applying existing technical capacities to create easy-to-assemble monitoring devices is vital for improving the availability of such devices to observation programs associated with the availability of water resources and the sustainability of integrated water resources management [13]. The central idea is to enhance tools available for obtaining the knowledge needed for risk assessment, environmental management, and decision-making, leading to the sustainable development of wetland ecosystems. The aim of this paper is to describe a saucer-shaped buoy we developed, including its internal electronics, remote-control unit, and operating software of our own design. This buoy and its systems are capable of following water motions and operating over short timescales (a few hours to 1 day) and distances (tens of meters to several kilometers).

\section{Materials and methods}

\subsection{Saucer-shaped buoy development}

The buoy domes were made from floats for domestic water tanks, while the stabilizing ring was made from a pair of plastic cutting boards that were fastened together with M6 stainless steel screws (Fig. 1). These materials can be obtained easily from local businesses. A polyvinyl chloride bell-shaped cone was mounted to the top of the buoy. This cone had a cap that held an input-output interface. The buoy dimensions were a diameter of $0.215 \mathrm{~m}$ and height of $0.167 \mathrm{~m}$.

The stabilizing ring comprised two circular ground disks. Each disk had a center hole with beveled seat, and the domes were pressed between the disks. In one of the disks, two circular slits served as seats for two rubber O-rings to prevent seepage of water into the domes. Tests in pools and in the field verified that the saucertype buoys were waterproof.
Fig. 1 Saucer-shaped drifters with input-output interface and handheld remote-control unit

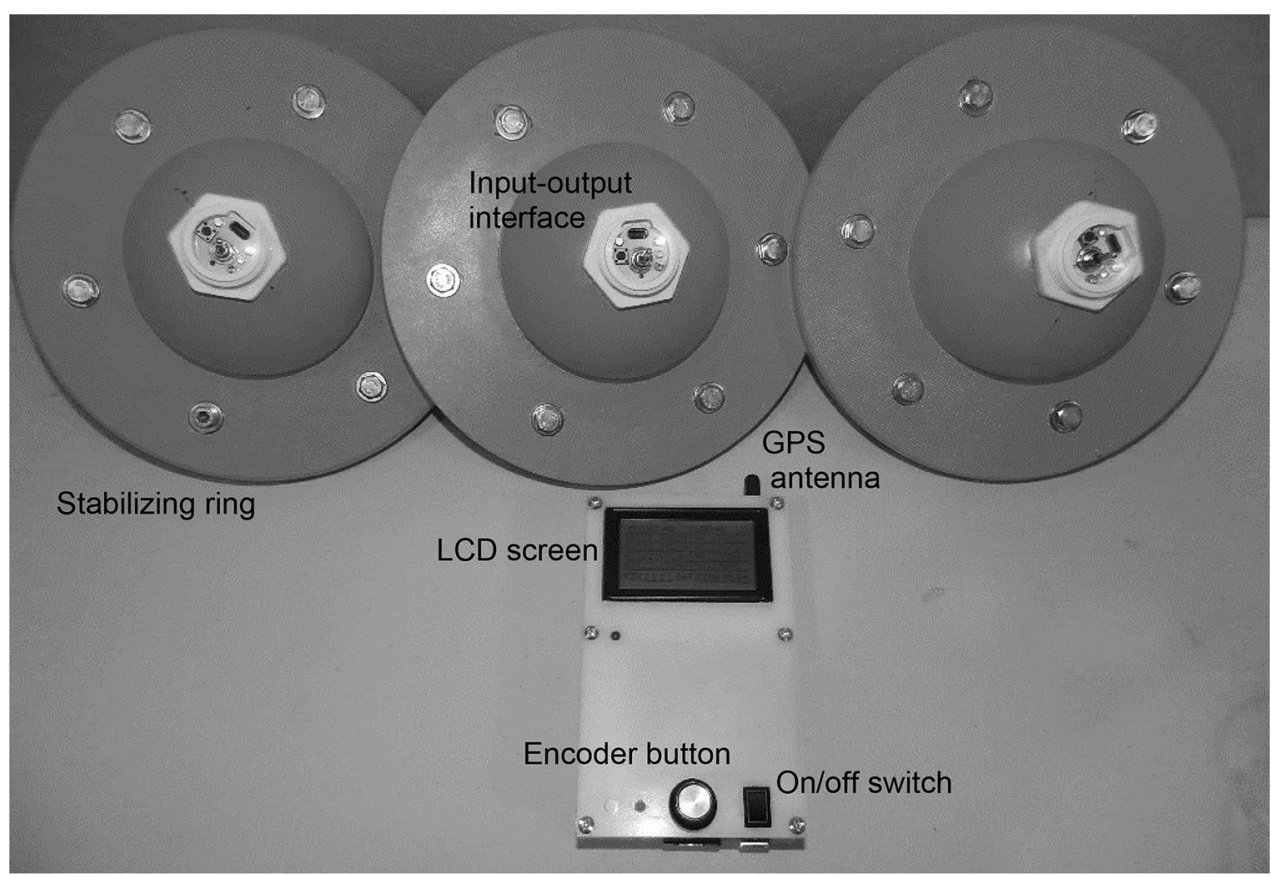




\subsubsection{Remote-control unit}

Figure 1 shows the handheld controller that wirelessly controlled and monitored the functions of the internal electronics of the drifters. A 32-bit MK20DX256 microcontroller (Table 1) ran algorithms for communication and wireless control of the GPS receiver, the input-output interface, data backup in a secure digital (SD) memory card, and energy management. A liquid crystal display (LCD) screen displayed system information. The encoder multifunction button was the primary user interface for the remote-control system. By simply clicking and/or turning the encoder button, the user could access different menus and select parameters to make programming changes to the buoys individually. The unit emitted an alarm buzz whenever it detected events that compromised the performance of the drifters, such as low batteries or buoy tip-over.

The housing of the remote-control unit was made of nylon cutting boards (Fig. 1). The top held the graphic display, battery, and secondary interface circuit, while the lower board held the main circuit. Screws fastened both covers to the sides, which were made of acrylic. Dimensions were $0.164 \mathrm{~m}$ long, $0.090 \mathrm{~m}$ wide, and $0.044 \mathrm{~m}$ high.

The remote-control unit provided information about buoy performance in real time, along with buoy position and state of battery charge, giving great versatility to the handling of drifters in the field. The remote-control telemetry algorithm could monitor up to ten buoys.

\subsubsection{Internal electronics}

Each buoy had an embedded control system comprising an 8-bit ATmega32u4 microcontroller (Table 1), GPS receiver, batteries, wireless telemetry system, micromemory card, and input-output user interface. The microcontrollers in the remote-control unit and the buoy perform the following functions: information and energy management, telemetry, GPS data acquisition, and data storage. The ATmega32u4 microcontroller was used in the buoy because it allows the access by computer to the SD card through the micro-universal serial bus (USB) port of the buoy, thus extracting the text files that contain the stored data of the GPS. The remote-control unit contains more peripherals (LCD display, multifunction button, etc.) than the electronic buoy system. For this reason, the MK20DX256 microcontroller was selected to manage the remote-control unit. In addition, it has a higher operating speed than the ATmega32u4, as well as a greater amount of program memory. A D25223T GPS was used to collect drifter position. The GPS module uses the general NMEA0183 format (National Marine Electronics Association) for data transmission, and the microcontroller of each buoy processes the data sent by the GPS in this format. Only the following types of strings are utilized: global positioning system fix data (GGA), vector track and speed over the ground (VTG), and recommended minimum data for GPS (RMC). For each string, the microcontroller selects information about latitude, longitude, number of satellites for using latitude and longitude data calculation and data mode: GPS Standard Positioning Service (GPS SPS) or Differential GPS Standard Positioning Service (DGPS SPS). Telemetry was based on an XBee PRO S1 1802.15.4 radio, which communicated with the remote-control unit to receive commands, such as start, pause, and stop data acquisition, and transmit GPS position, sampling time, and battery status. The XBee is a programmable wireless radio transmitter-receiver module that uses the Institute of Electrical and Electronics Engineers (IEEE) IEEE802.15.4 networking protocol for fast point-to-multipoint or peerto-peer networking. The buoy and the control-remote unit have both an XBee inside. The buoy microcontroller selects the GPS data information and sends it to the XBee through a universal asynchronous receiver/transmitter or UART (serial) communication. Then, the XBee in the buoy receives the GPS data information from the microcontroller and transmits it to the $\mathrm{XBee}$ receiver inside the remote-control unit and immediately thereafter from the XBee to the microcontroller in the remote-control unit using the UART communication. The microcontroller receives and processes this data to be displayed on the LCD screen. The maximum range in open areas free of interference was up to $1.5 \mathrm{~km}$. A lithium-polymer battery provided energy to the electronics system, and a button cell supplied power for GPS backup.

The input-output user interface consists of a USB communication port, light-emitting diode (LED) indicator for
Table 1 Manufacturer details for drifter components

\begin{tabular}{lllll}
\hline Equipment & Manufacturer name & City & State & Country \\
\hline MK20DX256 & NXP Semiconductors Netherlands B.V. & Eindhoven & - & The Netherlands \\
ATmega32u4 & Atmel Corporation & San Jose & CA & USA \\
D25223T GPS & ADH Technology Co. Ltd. & Taichung & - & Taiwan \\
XBee Pro S1 & Digi International Inc. & Minnetonka & MN & USA \\
MPC73831T & Microchip Technology Inc. & Chandler & AZ & USA \\
MAX17043 & Maxim Integrated & San Jose & CA & USA \\
\hline
\end{tabular}


battery status, multifunctional LED indicator, LED power indicator, LED indicator for GPS, and pushbutton and lever switches. The mini-USB port allowed extraction of information stored in memory, installation of operating software updates, and battery recharging. The battery provided enough energy for an average $10 \mathrm{~h}$ of operation. It is important to emphasize that the XBee PRO S1 1802.15.4 is solely for radio communication. While the microcontrollers manage and store in the SD memory card all the received GPS data, the ATmega32u4 can manage the USB port for extracting data to a computer. The MK20DX256 has only a standard SD slot.

The user interface was very convenient because it was not necessary to disassemble the buoys to recharge the batteries, and information could be extracted by simply connecting the buoy to a computer with a mini-USB cable. Additionally, a tilt sensor detected whether the drifter had been overturned by waves or struck by objects floating in the water. The MPC73831T integrated circuit performed safe and efficient recharging of the GPS battery, while the MAX17043 integrated circuit monitored the status of the GPS battery power. The final assembly of electronic components is shown in Fig. 2. The weight of internal electronics was $325 \mathrm{~g}$, and the total weight of the drifter in air was $1030 \mathrm{~g}$.

\subsection{Software development}

The control software was developed with Arduino (Hex binary file available under request), and it operated as described in this section. When each buoy is turned on, the software performs a series of tests to verify the USB connection, internal storage memory, battery charge, telemetry system, and access to GPS satellite signals. If any of these tests fail, the LED indicators in the input-output

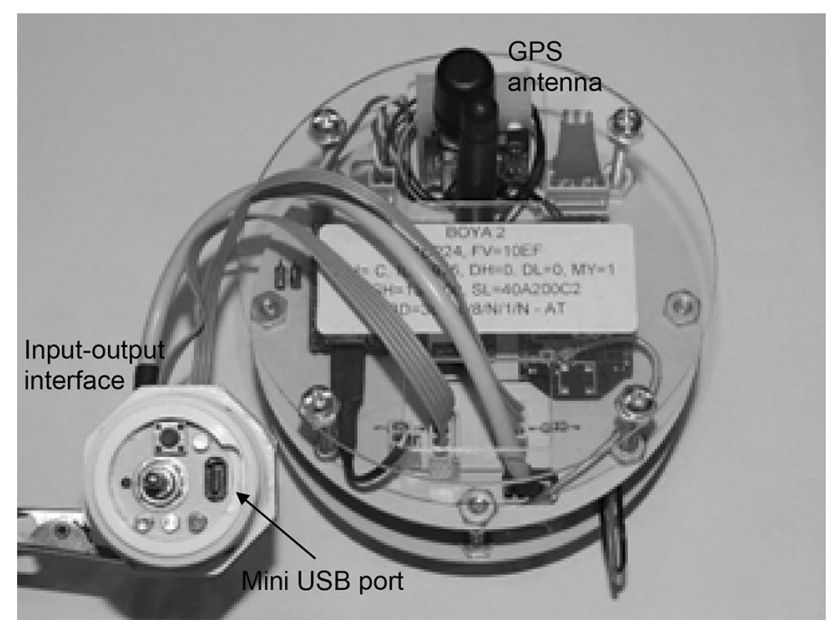

Fig. 2 Top view of electronic components user interface provide a visual alert. The GPS indicator will start flashing once data are valid, which can be visually verified on the LCD screen of the handheld controller. The buoy is ready to start operating at this point, and it is only necessary to send the start command either by pressing the encoder button on the controller or the pushbutton switch of the user interface. If any anomaly occurs at the start of data acquisition, the multifunction indicator will flash.

When the handheld controller is turned on, the software tests the internal storage memory and battery charge. A visual alert is displayed on the LCD screen if either of these tests fails. Then, the main menu lists the positions of the available buoys and the controller position, the detected satellite number, and the GPS accuracy $(<2.5 \mathrm{~m}$ or $<2.0 \mathrm{~m})$. The software also provides three different sub-menus that can be accessed via the encoder button. A first sub-menu displays the distance, direction, and the angle between the controller and each buoy. The second sub-menu shows the voltage, battery charge percentage, and the state of the internal memory. The third sub-menu is used for programming the buoy sampling times and GPS acquisition data. The default sampling time is $1 \mathrm{~s}$, which is the maximum sampling rate of the D25223T GPS.

\subsection{Surface dispersion of drifters}

Drifter motion follows the motion of passive fluid particles. Thus, the spreading of a group of drifters by advection and diffusion on the water surface can be used to infer dispersion characteristics of a fluid parcel. The mean rate of separation of fluid particles in the horizontal direction is related to the rate of change of the variance of particle positions. The separation rate is ideally estimated from a large ensemble of particles (drifters) released in open or closed water bodies [7]. The rate of dispersion of particle positions depends on the size of eddies present in the turbulent water motion, typically represented by a range of eddy scales, constituting what is known as relative dispersion [14]. Relative dispersion has been estimated in the field by observing the positions of drifters following the motions of particles in pairs $[14,15]$.

At short timescales, drifter dispersion is obtained as a mean of the two-dimensional variance of individual drifter positions relative to the cluster centroid [10]. That is, $\sigma_{i}^{2}=0.5\left(\sigma_{x i}^{2}+\sigma_{y i}^{2}\right)$, where $\sigma_{i}^{2}$ is the variance at time $i$ and $\sigma_{x i}^{2}$ and $\sigma_{y i}^{2}$ are the variances in the $x$ (east) and $y$ (north) coordinates given by $\sigma_{x i}^{2}=\frac{\sum_{j}\left(x_{i j}-\bar{x}_{i}\right)^{2}}{(N-1)}$ and $\sigma_{y i}^{2}=\frac{\sum_{j}\left(y_{i j}-\bar{y}_{i}\right)^{2}}{(N-1)}$, respectively. Here, $\left(x_{i j}, y_{i j}\right)$ are the position coordinates of $N$ drifters with cluster centroid $\left(\bar{x}_{i}, \bar{y}_{i}\right)$ given by $\bar{x}_{i}=\frac{\sum_{j} x_{i j}}{N}$ and $\bar{y}_{i}=\frac{\sum_{j} y_{i j}}{N}$. The dispersion coefficient dependence on scale is given by the $4 / 3$ power law [14-16]: $K\left(\ell_{0}\right) \propto \ell_{0}^{k}$. 
Here, $K\left(\ell_{0}\right)=\overline{\left(\ell_{1}-\ell_{0}\right)^{2}} / 2 T$ is the relative dispersion coefficient; $\ell_{0}$ and $\ell_{1}$ are the initial and final separation, respectively, of pairs of particles floating on the water surface, with the bar indicating the mean of all pairs; $T$ is the elapsed time between initial and final measurements of particle separation. The exponent $k$ ranges between 1.3 and 1.5 [15]. It is assumed that the relative motion of two particles is embedded in a homogeneous, stationary turbulent flow, where sufficiently small time has elapsed for particle-pair separations such that their positions are independent of $\ell_{0}$. However, this dispersion relationship has been derived from other theories of turbulent dispersion without this constraint. Thus, scale dependence applies over scales of $10 \mathrm{~m}$ to $1000 \mathrm{~km}$ in the ocean [9]. In practice, it is difficult for all measurements of a dispersing cluster to have the same $\ell_{0}$; therefore, a mean value, $\ell_{\mathrm{av}}=\left(\ell_{1}+\ell_{0}\right) / 2$, is taken over all pairs such that $\kappa\left(\overline{\ell_{\mathrm{av}}}\right)=\overline{\left(\ell_{1}-\ell_{0}\right)^{2}} / 2 T$.

\section{Results}

The ability of drifters to obtain reliable data was proved in the field by releasing a low-density cluster formed by three drifters at a freshwater inland wetland known as Estero Topila, Veracruz $\left(22^{\circ} 00^{\prime} 07.30^{\prime \prime} \mathrm{N}, 98^{\circ} 11^{\prime} 17.33^{\prime \prime} \mathrm{W}\right)$. This is a small, narrow body of water with depth less than $2 \mathrm{~m}$ that receives water only from the Pánuco River and runoff, both during the rainy season. Initial buoy separation was $4 \mathrm{~m}$, and raw positions from the drifters were converted to Universal Transverse Mercator coordinates. The test duration was $18 \mathrm{~min}$ with a sampling rate of $1 \mathrm{~s}$ (Fig. 3).

Drifter variance showed two distinct stages in the evolution of the centroid path. The first stage, up to about $360 \mathrm{~s}$ after release, was characterized by a steady decrease in $\sigma_{x^{\prime}}^{2}$ where buoys tended to be clustered, and hence, dispersion was low. Since no fluctuations were evident, drifters were probably advected by a uniform weak flow.
Figure 4 shows the time series of drifter variance after $360 \mathrm{~s}$ of flow, at which both $\sigma_{x}^{2}$ and $\sigma_{y}^{2}$ increased rapidly and buoys spread within the wetland. Variance fluctuations reflect small changes in the trajectory of the centroid, that is, rapid changes in the flow direction. However, in terms of the centroid velocity components, $\vec{V}=\left(\frac{\mathrm{d} \bar{x}_{i}}{\mathrm{~d} t}, \frac{\bar{y}_{i}}{\mathrm{~d} t}\right)=(u, v)$, the velocity fluctuations for the first $501 \mathrm{~s}$ after release of buoys are of the order of $(0.01,-0.1) \mathrm{cm} / \mathrm{s}$ and the second stage starts rather $502 \mathrm{~s}$ after deployment (Fig. 5).

To assess relative dispersion, the separation of drifters was calculated for all pairs. Separations smaller than $4 \mathrm{~m}$ were ignored and linearly interpolated to avoid uncertainties associated with GPS accuracy. To determine $K\left(\ell_{0}\right)$, initial and final separations of drifters were divided into short and long groups (Table 2) according to the median of $\ell_{0}$, or $852 \mathrm{~cm}$. Elapsed time was $30 \mathrm{~s}$, which is the same time used in the seawater experiment of [15]. Values for $\overline{\ell_{\text {av }}}$ and $K\left(\overline{\ell_{\mathrm{av}}}\right)$ for each group were $(541.2,37.0)$ and $(1470.0,148.7)$, respectively. The power law that fits these

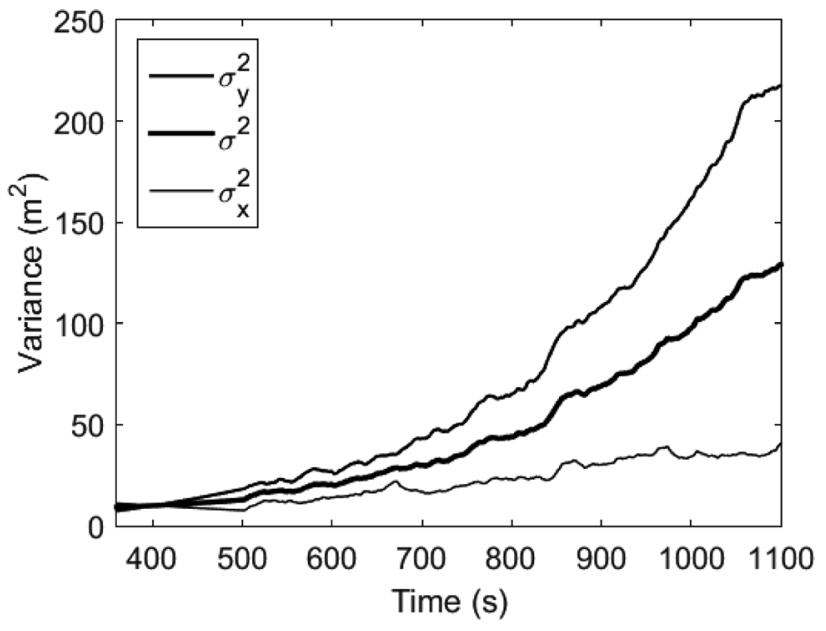

Fig. 4 Drifter dispersion $360 \mathrm{~s}$ after deployment
Fig. 3 Trio of drifters floating in Estero Topila, Veracruz, México

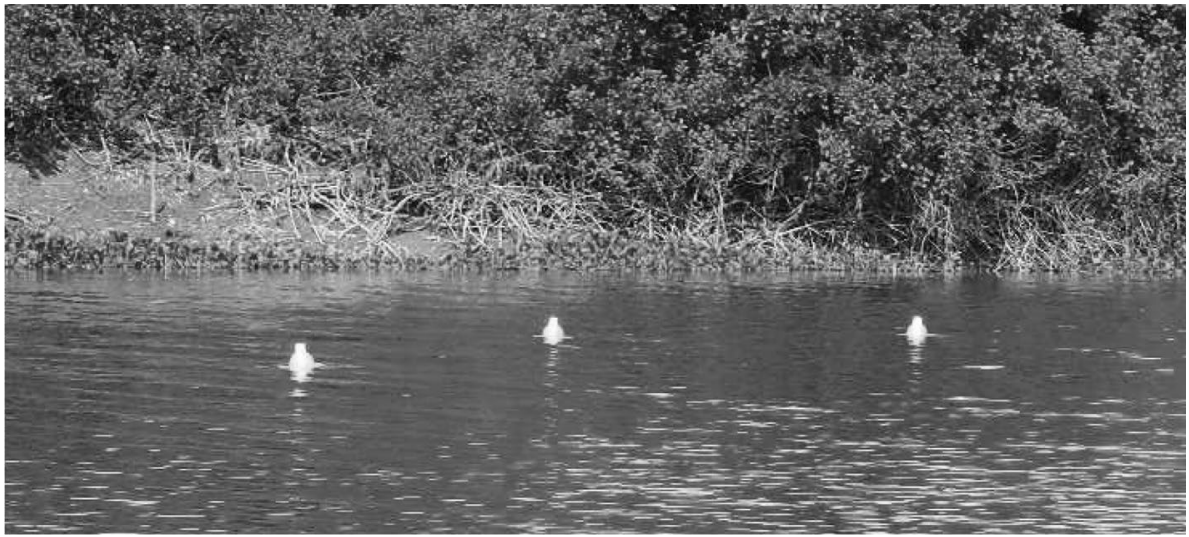

SN Applied Sciences a SPRINGER Nature journa 
Fig. 5 Variance ellipse of velocity components starting $502 \mathrm{~s}$ after deployment. Mean velocity $(3.6 \mathrm{~cm} / \mathrm{s})$ shown as a remarked black line

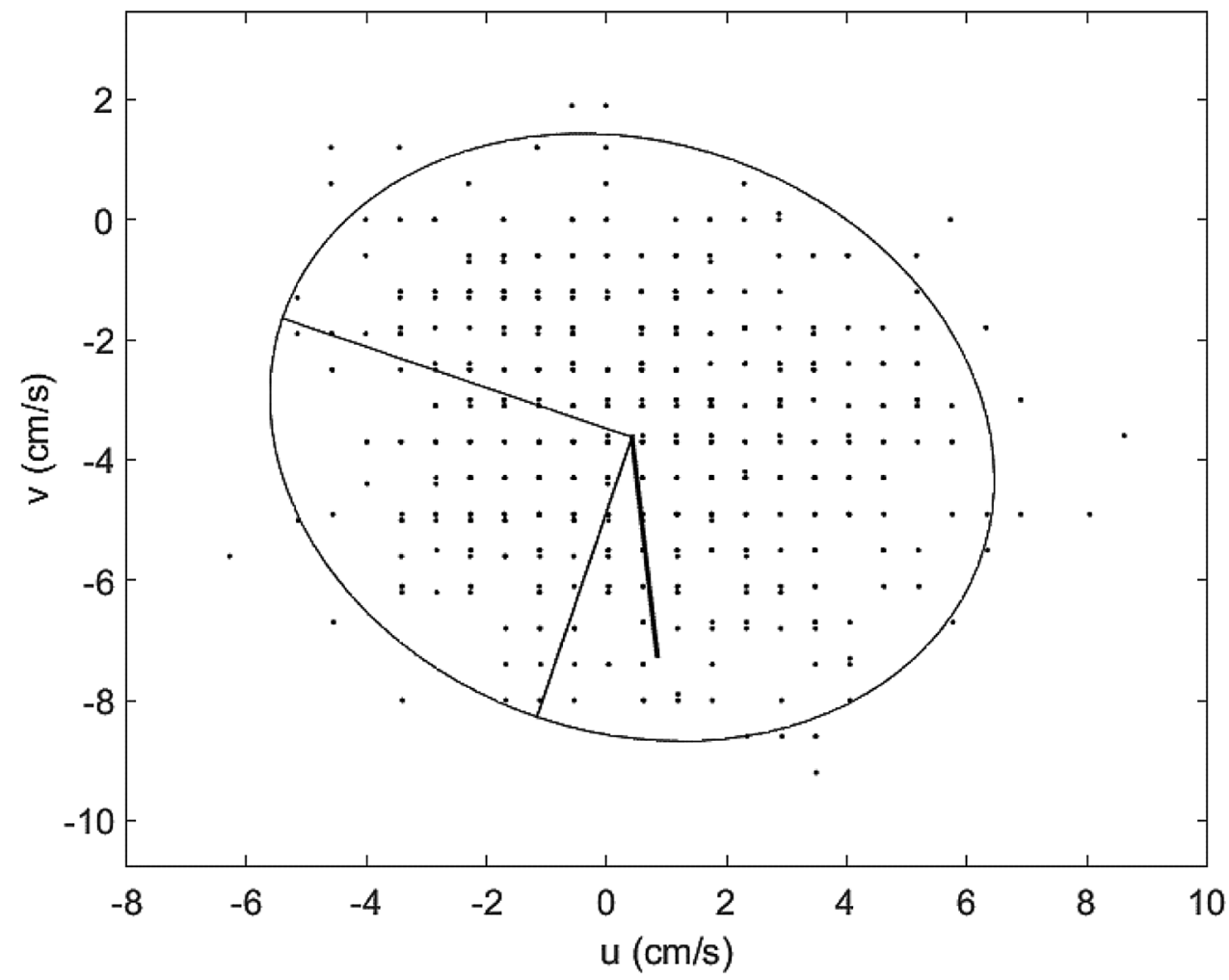

Table 2 Separation of drifter pairs measured at Estero Topila, divided into short and long separations using the median of $\ell_{0}$ as threshold criterion

\begin{tabular}{|c|c|c|c|c|c|c|c|c|c|c|c|}
\hline \multicolumn{6}{|c|}{ Short separations } & \multicolumn{6}{|c|}{ Long separations } \\
\hline$\ell_{0}(\mathrm{~cm})$ & $\ell_{1}(\mathrm{~cm})$ & $\ell_{0}(\mathrm{~cm})$ & $\ell_{1}(\mathrm{~cm})$ & $\ell_{0}(\mathrm{~cm})$ & $\ell_{1}(\mathrm{~cm})$ & $\ell_{0}(\mathrm{~cm})$ & $\ell_{1}(\mathrm{~cm})$ & $\ell_{0}(\mathrm{~cm})$ & $\ell_{1}(\mathrm{~cm})$ & $\ell_{0}(\mathrm{~cm})$ & $\ell_{1}(\mathrm{~cm})$ \\
\hline 553 & 463 & 370 & 359 & 595 & 640 & 1177 & 987 & 1410 & 1479 & 1604 & 1739 \\
\hline 624 & 524 & 821 & 820 & 390 & 455 & 987 & 948 & 1025 & 1048 & 924 & 1019 \\
\hline 463 & 452 & 460 & 473 & 640 & 676 & 948 & 914 & 1479 & 1565 & 2387 & 2493 \\
\hline 524 & 496 & 359 & 352 & 455 & 505 & 914 & 885 & 1048 & 1135 & 1739 & 1827 \\
\hline 452 & 444 & 820 & 826 & 676 & 830 & 885 & 860 & 1565 & 1639 & 1019 & 969 \\
\hline 496 & 470 & 473 & 489 & 505 & 447 & 860 & 841 & 1135 & 1122 & 2493 & 2657 \\
\hline 444 & 439 & 352 & 348 & 830 & 852 & 855 & 878 & 1639 & 1846 & 1827 & 1900 \\
\hline 470 & 445 & 826 & 837 & 447 & 508 & 878 & 906 & 1122 & 1245 & 969 & 1012 \\
\hline 439 & 437 & 489 & 506 & 508 & 536 & 906 & 939 & 1846 & 1853 & 2657 & 2828 \\
\hline 445 & 423 & 348 & 349 & 536 & 543 & 939 & 976 & 1245 & 1325 & 1900 & 1965 \\
\hline 437 & 439 & 837 & 855 & 543 & 543 & 976 & 1073 & 1853 & 1969 & 1012 & 1073 \\
\hline 423 & 402 & 506 & 526 & 543 & 610 & 1073 & 1168 & 1325 & 1430 & 2828 & 2992 \\
\hline 439 & 443 & 349 & 354 & 610 & 607 & 1168 & 1168 & 1969 & 2251 & 1965 & 2004 \\
\hline 402 & 385 & 526 & 547 & 607 & 782 & 1168 & 1220 & 1430 & 1524 & 1073 & 1135 \\
\hline 841 & 828 & 354 & 362 & 782 & 735 & 852 & 888 & 893 & 903 & 2992 & 3105 \\
\hline 443 & 450 & 547 & 570 & 735 & 769 & 1220 & 1326 & 2251 & 2280 & 2004 & 2047 \\
\hline 385 & 370 & 362 & 375 & 769 & 893 & 888 & 961 & 1524 & 1604 & 1135 & 1211 \\
\hline 828 & 821 & 570 & 595 & & & 1326 & 1410 & 903 & 924 & 3105 & 3205 \\
\hline 450 & 460 & 375 & 390 & & & 961 & 1025 & 2280 & 2387 & & \\
\hline
\end{tabular}

$\ell_{0}$ and $\ell_{1}$ are, in respective order, the initial and final separation of all pairs of drifters after an elapsed time of $30 \mathrm{~s}$ 
two groups, using linear least squares, is $K(\ell)=0.0058 \ell^{1.39}$, where the constant has the units $\mathrm{cm}^{2 / 3} \mathrm{~s}^{-1}$.

\section{Discussions}

The observations of [15] were done with parsnip, because they are almost completely immersed, and under slight wind conditions in seawater. Although during our field test, there was a combination of calm conditions and moderate wind gusts, the exponent agreement with Richardson's 4/3 power law is quite remarkable and is evident that the effect of wind on the upper dome of the drifting buoys was not significant. However, the latter does not prove that wind drag is not significant. Since it is likely that the buoys did not move mainly in the instantaneous wind direction, they followed the mean flow and were influenced by turbulent fluctuations associated with eddying motion in the water. Furthermore, this particle-pair dispersion in agreement with the 4/3 power law was achieved using high-resolution temporal data obtained by three drifters released in a small wetland. This proved that the electronic system worked properly and provided reliable position data. Shear-induced dispersion in the wetland appears to have influenced the separation of drifters. Temporal and spatial variability in the local wind regime is likely to develop horizontal velocity gradients on the water surface. These velocity gradients drove a rotational state of motion, an eddying motion in a range of scales (background turbulence).

The drifters have been developed protruded on purpose because we do not want to lose them, which limits their use after midday, when wind generally starts to blow over the local wetlands. In order to decrease the wind drag on the air side of the drifter and to increase drag in the fraction of the drifter below the water, it is possible to use both a drogue and a single thin acrylic stabilizer ring instead of two rough plastic cutting boards. However, the former is avoided because local freshwater lagoons are very shallow and colonized by submerged and emergent macrophytes that can produce the entrapment of drifters. To minimize the fraction of the drifter above the surface and therefore the wind contribution, it is relatively easy to include extra weight inside the buoy domes.

The housing of both buoy and handheld controller was made from inexpensive and easily available commercial materials, and the total cost of each buoy and remote-control unit resulted in roughly $\$ 200$ (USD) and \$250 (USD), respectively. The assembly of each buoy required about $40 \mathrm{~h}$. Although the buoy assembly was easy to perform, the cuts in the dome and disk caps were the hardest to achieve because it depended on the mechanical lathe operator's ability. This difficulty was solved by trial and error, as the operator gained more experience in performing the cuts. The use of a 3D printer would reduce the manufacturing time of domes and circular ground disks. Further, the use of a three-buoy system and a remote-control unit involves multiple transmissions of information to a single receiver. We found no data loss in the transmission of information during the fieldwork. In any case, the recorded data are stored in each of the buoys and can be downloaded later. It is expected that a number of 8-10 buoys are feasible for real-time data gathering without major latency issues with the technology developed in the present design.

\section{Conclusion}

This work developed a low-cost saucer-shaped drifter prototype appropriate to study small-scale turbulence in wetlands. The main characteristics of the GPS-equipped drifter are a user interface that allows the extraction of data without accessing the internal electronics and a remote-control unit that displays the performance of the buoy in real time. The saucer-shaped drifter is a practical tool developed from an innovative combination of existing technology. Despite drifters have been successfully tested in a low-advection freshwater body, a second prototype is needed to minimize wind drag and additional fieldwork to evaluate buoy performance under a wide variety of wind different conditions. For the time being, the current design is adequate for carrying out fieldwork in the mornings, before the wind begins to blow.

Acknowledgements We thank Oscar Velasco-Fuentes and María Beardslee-Origel for critically reviewing and editing an earlier manuscript draft. We also thank David MacDonald and Bryan Schmidt from Edanz Group (www.edanzediting.com/ac) for reviewing and editing a draft of this manuscript. Comments provided by anonymous reviewers substantially improved the manuscript and are greatly valued.

Funding This project was funded by Instituto Politécnico Nacional (Grant Number SIP-20120616) and Consejo Nacional de Ciencia y Tecnología (Grant Number CONACyT-FOMIX Tamaulipas 175692).

\section{Compliance with ethical standards}

Conflict of interest The authors declare that they have no conflict of interest.

\section{References}

1. Kingsford RT, Basset A, Jackson L (2016) Wetlands: conservation's poor cousins. Aquatic Conserv Mar Freshw Ecosyst 26:892-916. https://doi.org/10.1002/aqc.2709

2. OhImann JC, Molemaker MJ, Baschek B, Holt B, Marmorino G, Smith G (2017) Drifter observations of submesoscale flow 
kinematics in the coastal ocean. Geophys Res Lett 44:330-337. https://doi.org/10.1002/2016GL071537

3. Welander P (1955) Studies of the general development of motion in a two-dimensional, ideal fluid. Tellus 7:141-156. https ://doi.org/10.1111/j.2153-3490.1955.tb01147.x

4. Stocker R, Imberger J (2003) Horizontal transport and dispersion in the surface layer of a medium-sized lake. Limnol Oceanogr 48:971-982. https://doi.org/10.4319/lo.2003.48.3.0971

5. Schielicke L, Névir P, Ulbrich U (2016) Kinematic vorticity number, a tool for estimating vortex sizes and circulations. Tellus $A$ 68:1-20. https://doi.org/10.3402/tellusa.v68.29464

6. Lumpkin L, Özgökmen T, Centurioni L (2017) Advances in the application of surface drifters. Annu Rev Mar Sci 9:59-81. https ://doi.org/10.1146/annurev-marine-010816-060641

7. List J, Gartrell G, Winant CD (1990) Diffusion and dispersion in coastal waters. J Hydrol 116:1158-1179. https://doi.org/10.1061/ (ASCE)0733-9429(1990)116:10(1158)

8. Tseng R-S (2002) On the dispersion and diffusion near estuaries and around islands. Estuar Coast Shelf S 54:89-100. https://doi. org/10.1006/ecss.2001.0830

9. Johnson D, Pattiaratchi C (2004) Transient rip currents and nearshore circulation on a swell-dominated beach. J Geophys Res 109:C02026. https://doi.org/10.1029/2003JC001798
10. Ages $A B$ (1982) The development of an oilspill tracking technique. In: Canadian Technical Report of Hydrography and Ocean Sciences, vol 8

11. Goodman RH, Simecek-Beatty D, Hodgins D (1995) Tracking buoys for oil spills. In: International oil spill conference proceedings, pp 523-534

12. Fingas M (2011) Buoys and devices for oil spill tracking. In: International oil spill conference proceedings, pp 213-228

13. Koop SHA, van Leeuwen CJ (2017) The challenges of water, waste and climate change in cities. Environ Dev Sustain 19:385418. https://doi.org/10.1007/s10668-016-9760-4

14. Thorpe SA (2007) An introduction to ocean turbulence. Cambridge University Press, Cambridge

15. Richardson LW, Stommel H (1948) Note on eddy diffusion in the sea. J Meteorol 5:238-240

16. Summers DM (2005) Eddy diffusion in the sea: reinterpreting an early experiment. Proc R Soc A 461:1811-1827. https://doi. org/10.1098/rspa.2004.1433

Publisher's Note Springer Nature remains neutral with regard to jurisdictional claims in published maps and institutional affiliations. 